\title{
Relationship of Parental Burnout with Parental Stress and Personality among Parents of Neonates with Hyperbilirubinemia
}

\author{
Prof. Seema Vinayak ${ }^{1 *}$, Simplejit Kaur Dhanoa ${ }^{2}$
}

\section{ABSTRACT}

This study was designed to examine the inter-relationships between parental burnout, personality and parental stress among mothers as well as fathers of children with neonatal jaundice. The sample comprised with 200 parents, which were further divided into 100 parents of male neonates (i.e. 50 fathers and 50 mothers), 100 parents of female neonates (i.e. 50 fathers and 50 mothers). The results showed that the relationship exists between parental burnout, personality and parental stress among all the groups.

Keywords: Hyperbilirubinemia, Parental Burnout, Neonates

Neonates with hyperbilirubinemia are on higher risk of being diagnosed with autism or some other psychological development disorder later on in life compared to infants who did not have neonatal jaundice (Radha et al., 2012). The child with developmental delays may disrupt family routines, may require extra care, and create new stress in family relationships (Gray, 2003). Neonate with hyperbilirubinemia may cause a financial strain on family for medical specialists and for treatment. Since caring a sick neonate is demanding and difficult and requires additional effort, it is not surprising that parents of neonates with hyperbilirubinemia have reported the greatest levels of stress as compared to neonates without hyperbilirubinemia (Boyd, 2002; Herring et al., 2006).

The theoretical models of parental burnout have focused on two major sources. The first source is the well-known care giving and stress process model by Pearlin et al. (1990) that identifies stressors and role strains often encountered by caregivers who may lead to negative outcomes such as anxiety, depression, cognitive disturbances and problems with physical health. The second source is a model by Platt, Weyman, Hirsch \& Hewett (1980) that identifies a range of problematic behaviors and impaired functional abilities that have been linked to negative

\footnotetext{
${ }^{1}$ Professor Dept. of Psychology, Panjab University, Chandigarh, India

${ }^{2}$ Ph. D Scholar, Dept. of Psychology, Panjab University, Chandigarh, India

*Responding Author
}

Received: January 17, 2017; Revision Received: February 19, 2017; Accepted: February 25, 2017

(C) 2017 Vinayak S, Dhanoa S; licensee IJIP. This is an Open Access Research distributed under the terms of the Creative Commons Attribution License (www.creativecommons.org/licenses/by/2.0), which permits unrestricted use, distribution, and reproduction in any Medium, provided the original work is properly cited. 


\section{Relationship of Parental Burnout with Parental Stress and Personality among Parents of Neonates with Hyperbilirubinemia}

outcomes for the family members and friends. The primary stressors noted in the model include patient symptoms, disruptive patient behaviors, impaired patient role performance, issues of dependency, caregiver role overload/burnout and caregiver relational deprivation and their personality. Secondary stressors include family conflict, care giving/role conflict, caregiver concerns about the future, constriction of caregiver social activities and economic problems.

Parental burnout is a state of physical, emotional and mental exhaustion that may be accompanied by a change in attitude from positive to negative (Luecher et al., 1999). Burnout can occur when caregivers don't get the help they need either physically or financially. Parents who are "burn out" may experience fatigue, stress, anxiety and depression (Kasuya et al., 2010). Parents often are so busy caring for others that they tend to neglect their own emotional, physical and spiritual health. The demands on a caregiver's body, mind and emotions can easily seem overwhelming, leading to fatigue, hopelessness and ultimately burnout. Other factors that can lead to parental burnout may include role confusion, unrealistic expectations, lack of control and unreasonable demands. Considering the seriousness of the physical exhaustion syndrome, it is most important to identify parents with burnout symptoms as early as possible. In addition, psychological reactions may affect the parent's ability to manage the child's treatment and also influence the child's development (Lindstrom et al., 2009).

Parental stress is a specific kind of stress perceived by parent and emanating from the demands of being a parent (Berry \& Jones, 1995). Parental stress is a complex construct that involves behavioral, cognitive and affective components. It is a combination of child and parents characteristics as well as family situational components as they relate to the person's appraisal of his or her role as a parent (Herring et al., 2006). Parental stress has been described as the difficulty that a parent feels or experiences while watching their children in pain. Parental stress consists of parent related variables (e.g. parent psychological wellbeing), child related variables (e.g. child characteristics) and negative life events (Rondo et al., 2003). Duygun \& Sezgin (2003) reported that parental burnout occurs with persisting demands of the family's needs. These persisting demands deplete the motivation of the parents and they may experience the emotions of self-blame and anger. Caregiver burnout is the final step in the progression of caregiver burden/stress, where the experience is no longer healthy for both the caregiver and the person receiving care.

Personality is the particular combination of emotional and behavioral response patterns of an individual. Personality refers to the organized pattern of behavioural characteristics that are the working result of the distinguishing physical, mental, emotional and social features of an individual person (Digman, 1990). According to McCrae \& Costa (1992) Personality is usually broken into components called the Big Five, which are openness to experience (degree of intellectual curiosity, preference for novelty), conscientiousness (self-disciplined, planned and

(c) The International Journal of Indian Psychology, ISSN 2348-5396 (e)| ISSN: 2349-3429 (p) | 103 


\section{Relationship of Parental Burnout with Parental Stress and Personality among Parents of Neonates with Hyperbilirubinemia}

organized), extroversion (positive emotions, assertiveness and sociability), agreeableness (compassionate and cooperative) and neuroticism (experience unpleasant situation easily). These components are generally stable over time and appear to be attributable to a person's genetics rather than the effects of one's environment. Buhler et al. and Lingard (2003) found that extraversion is negatively associated with emotional exhaustion. Francis et al. (2004) and Zellars et al. (2000) found a negative association between extraversion and depersonalization Rossler et al. (2013) studied association between burnout and personality among the general population. The results identified a complex interaction between maladaptive personality and burnout.

\section{The aim of this study is to examine}

1. The relationship of parental stress, personality with burnout of the parents of neonates with hyperbilirubinemia.

2. The parental stress in parents of male and female neonates with hyperbilirubinemia.

3. The personality of parents of male and female neonates with hyperbilirubinemia.

\section{Hypotheses}

1. It is expected that there will be a positive relationship of parental burnout with

a. parental stress

b. personality viz. neuroticism

2. It is expected that there will be a negative relationship of parental burnout with a. personality viz. extraversion, openness, agreeableness and conscientiousness.

\section{Design}

This study has been designed to examine the inter-relationships of parental burnout with parental stress and personality among mothers as well as fathers of neonates with hyperbilirubinemia. The sample comprised of 300 parents, in the age range of 20-35 years. The sample was further divided into 100 parents of male neonates with hyperbilirubinemia (i.e. 50 fathers \& 50 mothers) and 100 parents of female neonates with hyperbilirubinemia (i.e. 50 fathers \& 50 mothers). The findings of the study revealed that there is relationship among parental burnout, parental stress and personality. Parents of neonates having bilirubin level $17 \mathrm{mg} / \mathrm{dl}$ to $24 \mathrm{mg} / \mathrm{dl}$ and have preterm first live bon baby with gestational age between 35to 38 weeks were included. Parents with educational qualification at least higher secondary and belonging to middle socio economic status were taken. Mothers who were non-working and parents belongs to nuclear family were included in this study.

\section{Tests and Tools}

The following standardized tests and tools would be used to collect the data:

\section{Maslach Burnout Inventory (MBI):}


MBI is a 22-item instrument developed by Maslach \& Jackson (1986) to assess the three components of the burnout syndrome:

(a) Emotional Exhaustion, measures feelings of being emotionally overextended and exhausted by one's work.

(b) Depersonalization measures an unfeeling and impersonal response towards recipients of one's service, care treatment or instructions and

(c) Lack of Personal Accomplishment, measures feelings of competence and successful achievement in one's work.

The respondents answer the statements about personal feelings or attitudes in terms of how frequently they experienced the stated situation on a 7-point scale. It is adapted and translated by Ergin (1992), and the 7-point scale was converted into a 5-point scale (0=never; 4=always). Duygun \& Sezgin (2003), changed the instructions of the questionnaire into "my child" instead of "my recipients" and "the care of my child" instead of “my work” or "my job”. Duygun \& Sezgin (2003), found that the MBI had two factors in a sample of mothers who had mentally retarded children. In his study, the Cronbach Alpha values were .80 for both emotional exhaustion and lack of personal accomplishment factors. In the present study, the alpha values were .87 for emotional exhaustion, .74 for lack of personal accomplishment and .85 for total burnout scale.

\section{The Parental Stress Scale (PSS):}

This scale was developed by Berry \& Jones, 1995. The PSS is a self-report scale that contains 18 items representing pleasure or positive themes of parenthood (emotional benefits, self-enrichment, personal development) and negative components (demands on resources, opportunity costs and restrictions). Respondents are asked to agree or disagree with items in terms of their typical relationship with their child or children and to rate each item on a five-point scale: strongly disagree (1), disagree (2), undecided (3), agree (4), and strongly agree (5). The 8 positive items are reverse scored so that possible scores on the scale can range between 18-90. Higher scores on the scale indicate greater stress. The scale is intended to be used for the assessment of parental stress for both mothers and fathers and for parents of children with and without clinical problems. The scale demonstrated satisfactory levels of internal reliability (.83), and test-retest reliability (.81). The scale demonstrated satisfactory convergent validity with various measures of stress, emotion and role satisfaction including perceived stress, work/family stress, loneliness, anxiety, guilt, marital satisfaction, marital commitment, job satisfaction and social support. Discriminant analyses demonstrated the ability of the scale to discriminate between parents of typically developing children and parents of children with both developmental and behavioral problems.

\section{NEO-Personality Inventory (Big-5):}

Big-5 was developed by Costa \& McCrae, 1985. Big five is a self report inventory of 44 items. It designed to measure big five personality dimensions. Each of the factors is further 
Relationship of Parental Burnout with Parental Stress and Personality among Parents of Neonates with Hyperbilirubinemia

divided into personality facets: OCEAN; Openness, Conscientiousness, extraversion, Agreeableness and Neuroticism. It represents a biological account of personality traits as well as environmental influences, such as social roles combines with biological influences in shaping personality traits.

(a) The Openness means people who like to learn new things and enjoy new experiences usually score high in openness. It includes traits like being insightful, imaginative, lives in fantasies and having vided variety of interests.

(b) The Conscientiousness means people that have a high degree of conscientiousness are reliable and prompt. Traits include being organized, methodical, competence, order, dutifulness, achievement striving, self discipline and deliberation.

(c) The Extraversion; extraverts get energy from interacting with others, while introverts get energy from within themselves. Extraversion includes the traits of sociable, energetic, assignment seeking, assertiveness, positive emotions and warmth.

(d) The Agreeableness, these individuals are friendly, cooperative and compassionate, traits include being kind, affectionate, sympathetic, forgiving, not demanding, warm, compliance, tender mindedness and modesty.

(e) The Neuroticism is also sometimes called emotional stability. This dimension relates to one's emotional stability and degree of negative emotions. The traits include being moody, tense, anxiety, anger hostility, depression, self consciousness, Impulsiveness and vulnerability. The internal reliability range between .87 to .92.

\section{Statistical Analysis}

To meet the objectives of the study, descriptive statistics viz. mean, Standard Deviation, correlation will be studied.

\section{RESULTS}

Table 1: Shows the Correlation of Parental Burnout with Parental Stress and Dimensions of Personality

\begin{tabular}{|l|l|l|l|l|l|l|}
\hline $\begin{array}{l}\text { Parental } \\
\text { Burnout }\end{array}$ & $\begin{array}{l}\text { Parental } \\
\text { Stress }\end{array}$ & Extraversion & $\begin{array}{l}\text { Agreeabl- } \\
\text { eness }\end{array}$ & $\begin{array}{l}\text { Conscietious- } \\
\text { ness }\end{array}$ & Openness & Neuroticism \\
\hline 1 & $.412^{* *}$ & $-.398 * *$ & -.044 & -.102 & $-.275^{*}$ & $.332^{* *}$ \\
\hline
\end{tabular}

$P<\ldots .05^{*}$ and $.01^{* *}$

Table 2: Shows the Correlation between Parental Burnout, Parental stress and Personality among Parents of Female neonates with neonatal Hyperbilirubinemia

\begin{tabular}{|l|l|l|l|l|l|l|}
\hline $\begin{array}{l}\text { Parental } \\
\text { Burnout }\end{array}$ & $\begin{array}{l}\text { Parental } \\
\text { Stress }\end{array}$ & Extraversion & $\begin{array}{l}\text { Agreeable } \\
\text { ness }\end{array}$ & $\begin{array}{l}\text { Conscietious } \\
\text { ness }\end{array}$ & Openness & Neuroticism \\
\hline 1 & $.392^{* *}$ & $-.251^{*}$ & -.001 & -.101 & $-.211^{*}$ & $.300^{* *}$ \\
\hline
\end{tabular}

$P<\ldots .05^{*}$ and $.01^{* *}$

(c) The International Journal of Indian Psychology, ISSN 2348-5396 (e)| ISSN: 2349-3429 (p) | 106 
Relationship of Parental Burnout with Parental Stress and Personality among Parents of Neonates with Hyperbilirubinemia

Table 3: Shows the Correlation between Parental Burnout, Parental stress and Personality among Parents of Male neonates with neonatal Hyperbilirubinemia

\begin{tabular}{|l|l|l|l|l|l|l|}
\hline $\begin{array}{l}\text { Parental } \\
\text { Burnout }\end{array}$ & $\begin{array}{l}\text { Parental } \\
\text { Stress }\end{array}$ & Extraversion & $\begin{array}{l}\text { Agreeable } \\
\text { ness }\end{array}$ & $\begin{array}{l}\text { Conscietious } \\
\text { ness }\end{array}$ & Openness & Neuroticism \\
\hline 1 & $.255^{*}$ & $-.242^{*}$ & -.010 & -.031 & -.001 & $.298^{*}$ \\
\hline
\end{tabular}

\section{DISCUSSION}

The aim of the present investigation was to study the relationship of parental burnout with parental stress and personality among parents of neonates with hyperbilirubinemia. The sample was categorized into parents of male and female neonates with hyperbilirubinemia.

For the present investigation purposive sample was comprise of 200 parents, in the age range of 20-35 years because we are taking the sample of first live born neonates with hyperbilirubinemia from the clinical setting. The sample was further divided into 100 parents of male neonates with hyperbilirubinemia (i.e. 50 fathers \& 50 mothers) and 100 parents of female neonates with hyperbilirubinemia (i.e. 50 fathers $\& 50$ mothers).

Those parents whose child was preterm with more than $17 \mathrm{mg} / \mathrm{dl}$ bilirubin level and with educational qualification of at least higher secondary level were included. The sample were taken from the government and private hospitals of Chandigarh as most of the patients from Punjab, Haryana and nearby areas come for the treatment of hyperbilirubinemia and also for the follow ups of the children.

Scoring for all the given tests was done as per the instructions provided in the scoring manuals of the tests. Normality of the data was assessed before conducting the statistical analysis. Correlation analysis was conducted to find out relationship of various variables with parental burnout. All groups were assessed on parental stress and on personality and their role with parental burnout.

The results showed positive inter-correlation between parental burnout and parental stress among all the groups and several studies supported the results. Stress among parents of disabled children and neurotic children undergo more stressful experiences. The care giving of severely ill children is so stressful that accompanied with burnout. The studies show positive correlation between parental stress and parental burnout (Gupta \& kaur, 2010; Faber et al., 2002; Hidangyum, 2010). The positive relationship revealed between the parental burden, social emotional burden, disruption of family routine and disturbance in family interactions among parents of intellectually disabled children (Seshadri et al., 2000). Giving birth to a mentally challenged or other critically ill child is an unexpected stressful event which affects the parents. Such an event may impair family development and may continue over time, affecting the entire family system.

(c) The International Journal of Indian Psychology, ISSN 2348-5396 (e)| ISSN: 2349-3429 (p) | 107 


\section{Relationship of Parental Burnout with Parental Stress and Personality among Parents of Neonates with Hyperbilirubinemia}

The impact of illness is associated with emotional and psychological stress and parents may face frequent fear, confusion, stigma and isolation which is correlated with parental burnout and burden (Hindmayum, 2010). Several studies showed (Barakat et al., 2006; Buchi et al., 2007; Engelkemayer \& Mewit, 2008; Hungerbuehler et al., 2011), that mothers report higher levels of growth than fathers (Barr, 2011; Buchi et al., 2007; Hungerbuehler et al., 2011) and that increasing seriousness of the potentially traumatizing event is related to higher PTG (Colville, 2009). The association also seems to be moderated by gender (Barakat et al., 2006).

Similarly, the findings of this study showed neuroticism and parental burnout are significantly positively correlated with among all the groups, hence, hypothesis (H1b) is significantly proved. Similarly, Extraversion and parental burnout are also significantly negatively correlated among all the groups. Openness to experience was significantly negatively correlated with parental burnout among total sample of parents and among parents of female neonates.

Most of the researches shows supporting role and revealed that burnout can be found both within and outside the human (Bakker, Demerouti \& Schaufeli, 2002), Caregivers of severely ill children are generally at relatively high risk for burnout (Schaufeli, 2003). Caregiver's oftenly confronted with emotionally demanding relationships with the recipients of their care. Such relationships are inherently difficult and upsetting because caregivers have to deal with sufferer as well as with the society. Neuroticism is significantly correlated with parental burnout among the caregivers of patients in metropolitan hospitals (Fancis et al., 2010, 2003). Studies reported social extraversion and action extraversion to be negatively associated with burnout (Francis et al., 2013 \& Zellars et al, 2000). A negative association was found between extraversion and parental burnout among caregivers of patients (Fancis et al, 2010; zellas et al., 2000; Buhler \& Land, 1996). Indeed, (Lingard, 2003) reported social extraversion and action extraversion to be negatively associated with burnout. Researchers (e.g., Deary et al., 1996; Hills \& Norvell, 1991; Lepine, Lepine, \& Jackson, 2004; Lingard, 2003; Zellars et al., 2000) on the relationship between neuroticism and burnout have typically shown that individuals who are high in neuroticism are more likely to report feelings of emotional exhaustion and to report lower levels of personal achievement. In a study of intensive-care nursing staff (Buhler \& Land, 2014) found that individuals who were higher in neuroticism experienced higher levels of emotional exhaustion and depersonalization. However, (Deary et al., 2003) noted a significant association between neuroticism at and emotional exhaustion among nursing students.

\section{CONCLUSION}

Parental Burnout occurs with persisting demands and these persisting demands deplete the motivation of the caregivers and they experience emotions of self blame. Here, personality plays a vital role in the development of burnout. Neurotistic persons are more prone towards stress and they have less coping abilities to deal with stressful situation while the other four dimensions

(c) The International Journal of Indian Psychology, ISSN 2348-5396 (e)| ISSN: 2349-3429 (p) | 108 


\section{Relationship of Parental Burnout with Parental Stress and Personality among Parents of Neonates with Hyperbilirubinemia}

personality can easily cope with trauma and may try to adjust and cope with the situation. So, the caregivers need special counselling sessions as well as the sessions to deal with and to manage with stressful situations especially during the hospitalization of their children.

\section{Acknowledgments}

The author appreciates all those who participated in the study and helped to facilitate the research process.

Conflict of Interests: The author declared no conflict of interests.

\section{REFERENCES}

Almberg, B., Grafstrom, M., Krichbaum, K., \& Winblad, B. (2000). The interplay of institution and family caregiving: Relations between patient hassles, nursing home hassles and caregivers’ burnout. International Journal of Geriatric Psychiatry, 15, 931-939.

American Academy of Pediatrics. (1995). Practice parameter: Management of hyperbilirubinemia in the healthy term newborn. Journal of Pediatrics, 95, 458-461.

Arnold, B. B., Kareni, V. D., Kerrya, L., \& Maureen, F. D. (2002). The relationship between the big five personality factors and burnout: A study among volunteer counselors. Journal of Social Psychology, 135, 456-68.

Berry, J. O., \& Jones, W. H. (1995). The parental stress scale: Initial psychometric evidence. Journal of Social and Personal Relationships, 12, 463-472.

Blumberg, N. L. (1980). Effects of neonatal risk, maternal attitude and cognitive style on early post-partum adjustment. Journal on Abnormal Child Psychology, 89, 139-150.

Boyd, B. A. (2002). Examining the relationship between stress and lack of social support in mothers of children with autism: Focus on autism \& other developmental disabilities. Journal of Child Psychology, 17, 208-215.

Brandson, D. H., Tully, K. P., Silva, S. G., Makolm, W. F., Turner, B. S., \& Davis, D. H. (2011). Emotional responses of mothers of late preterm and term infants. Journal of Obstetric, Gynecologic and Neonatal Nurses Issues, 40, 719-731. doi:10.1111/j.15526909.2011.01290.x

Buhler, K. E., \& Land, T. (2003). Burnout and personality in intensive care: An empirical study. Hospital Topics: Research and Perspectives on Health Care, 81, 5-12.

Bystrova, K., \& Ivanova, V. (2009). Early contact versus separation: effects on mother infant interaction one year later. Journal of Pediatrics, 36, 97-109.

Cadell, S., Regeur, C., \& Hemsworth, D. (2003). Factors contributing to posttraumatic growth: A proposed structural equation modeling. Anniversary Journal of Orthopsychiatry, 73, 279-287.

Calhoun, L. G., Cann, A., Tedeschi, R. G., \& McMillan, J. (2000). A correlational test of the relationship between posttraumatic growth, religion and cognitive processing. Journal of Traumatic Stress, 13, 521-527.

Calhoun, L. G., \& Tedeschi, R. G. (1999). Facilitating posttraumatic growth: A clinician's guide. Mahwah, NJ: Erlbaum.

Carol, R., Donal, G., Fortune, \& Prentice, G., (2013). Post-traumatic growth, illness perceptions and coping in people with acquired brain injury. Neuropsychological Rehabilitation: An International Journal, 78, 639-657. doi: 10.1080/09602011.2013.799076.

(c) The International Journal of Indian Psychology, ISSN 2348-5396 (e) | ISSN: 2349-3429 (p) | 109 


\section{Relationship of Parental Burnout with Parental Stress and Personality among Parents of Neonates with Hyperbilirubinemia}

Catz, C., Hanson, J., Simpson, L., \& Yaffe, S. (1995). Summary of workshop: early discharge and neonatal hyperbilirubinemia. Journal of Pediatrics, 96, 743-45.

Christian, N. (2010). Infant jaundice linked to higher risk of autism and psychological development disorders. Journal of Pediatrics, 80, 456-75.

Crnic, K. A., \& Booth, C. L. (1991). Mothers' and fathers' perceptions of daily hassles of parenting across early childhood. Journal of Marriage and the Family, 53, 1042-1050.

DeMier, R. L., Hynan, M. T., Hatfield, R. F., \& Maniello, R. L. (2000). A measurement model of perinatal stressors: identifying risk for postnatal emotional distress in mothers of highrisk infants. Journal of Clinical Psychology, 56, 89-100.

Duygun, T., \& Sezgin, N. (2003). The effects of stress symptoms, coping styles and perceived social support on burnout level of mentally handicapped and healthy children's mothers. American Journal on Mental Retardation, 18, 37-52.

Engelkemeyer, S. M., \& Marwit, S. J. ( 2008). Posttraumatic growth in bereaved parents. Journal of Traumatic Stress, 21, 344-346.

Francis, L. J., Louden, S. H., \& Rutledge, C. J. F. (2004). Burnout among Roman Catholic parochial clergy in England and Wales: Myth or Reality?. Review of Religious Research, 46, 5-19.

Gray, D. (2003). Gender and Coping: The parents of children with high functioning autism. Social Science Medicine, 56, 631-642.

Gallagher, S., \& Whiteley, J. (2012). The association between stress and physical health in parents caring for children with intellectual disabilities is moderated by children's challenging behaviour. Journal of Psychiatry, 45, 571-82.

Herring, S., Gray, K., Taffe, J., Tonge, B., Sweeney, D., \& Einfeld, S. (2006). Behavior and emotional problems in toddlers with pervasive developmental disorders and developmental delay: Associations with parental mental health and family functioning. Journal of Intellectual Disability Research, 50,874-882.

Jennifer, L., Callahan, M. S., \& Michael, T. (2009). Identifying mothers at risk for postnatal emotional distress: Further evidence for the validity of the perinatal posttraumatic stress disorder questionnaire. Journal of Perinitology, 22, 448-456.

Karanci, N. A., Alkan, N., Sucuolu, H., \& Balta, E. (1999). Gender differences among parents of autistic children in psychological distress, coping, social support and related variables to burnout. North American Journal of Psychology, 1, 189-204.

Kasuya, R. T., Bailey, P., \& Takeuchi, R. (2010). Caregiver burden and burnout. Postgraduate Medicine, 108, 119-123.

Kwan, M. Y. (2012). Parental stress in parents of children with disabilities. Journal of Psychiatry,2,11-21.

Lindstrom, C., Aman, J., \& Norberg, A. (2009). Increased prevalence of burnout symptoms in parents of chronically ill children. Journal of Pediatrics, 99,427-437, doi: 10.1111/j.1651-2227.2009.01586.x

Lindstrom, C., Aman, J., \& Norberg, A. L. (2011). Parental burnout in relation to sociodemographic, psychosocial and personality factors as well as disease duration and glycaemic control in children with type 1 diabetes mellitus. Journal of Pediatrics, 100, 1011-7. doi: 10.1111/j.1651-2227.2011.02198.x

Luecher, J. L., Dede, D. E., Giten, J. C., Fennel, E., \& Maria, B. L. (1999). Parental burden, coping and family functioning in primary caregivers of children with joubert syndrome.

(c) The International Journal of Indian Psychology, ISSN 2348-5396 (e) | ISSN: 2349-3429 (p) | 110 


\section{Relationship of Parental Burnout with Parental Stress and Personality among Parents of Neonates}

with Hyperbilirubinemia

Journal of Child Neurology, 14, 642-648.

Patricia, R., Hannon, M. D., Sharla, K., Willis, \& Susan, C. (2001). Persistence of maternal concerns surrounding neonatal jaundice. An Exploratory Study. Archives Pediatrics Adolescent Medicine, 155(12), 1357-1363. doi:10.1001/archpedi.155.12.1357.

Radha, L., Jaiswal, A., Reddy, P., \& Srinivas, M. (2012). Predictors of significant jaundice in late preterm infants in India. Indian Pediatrics, 49, 717-720. SII:S097475591100553-1.

Rondo, P., Ferreira, R. F., \& Nogueira, F. (2003). Maternal psychological stress and distress as predictor of low birth weight. European Journal of Clinical Nutrition, 57, 266- 72.

Rossler, W., Hengartner, M. P., Ajdacic, G. V., \& Angst, J. (2013). Association between burnout and personality: results of the Zurich study. Journal of Psychiatry, 84,799-805. doi: 10.1007/s00115-013-3742-7.

Schaufeli, W. B., \& Enzmann, D. (1998). The burnout campanion to study and practice: A critical analysis. London: Taylor and Francis.

Schoulte, J., Sussman, Z., Tallman, B., Comick, C., \& Altmaier, E. (2012). Is there growth in grief: measuring posttraumatic growth in the grief response. Journal of Medicine and Healthcare,1, 38-43. doi:10.4236/oimp.2012.13007.

Smith, B. W., Dalen, J., Bernard, J. F., \& Baumgartner, K. B. (2010). Posttraumatic growth in non-hispanic white and hispanic women with cervical cancer. Journal of Psychosocial Oncolology, 26, 91-109. doi: 10.1080/07347330802359768.

Smith, D., Fowler, J., DuBose, L., Saxton, D., \& Herbert, J. (2013). An osteopathic approach to reduction of readmissions for neonatal jaundice. Osteopathic Family Physician, 5, 57-65. doi:10.1016/j.osfp.2012.09.005.

Zellars, K. L., Perrewe, P. L., \& Hochwarter, W. A. (2000). Burnout in health care: The role of the five factors of personality. Journal of Applied Social Psychology, 30(8), 1570-1598.

How to cite this article: Vinayak S, Dhanoa S (2017), Relationship of Parental Burnout with Parental Stress and Personality among Parents of Neonates with Hyperbilirubinemia, International Journal of Indian Psychology, Volume 4, Issue 2, No. 92, ISSN:2348-5396 (e), ISSN:2349-3429 (p), DIP:18.01.112/20170402, ISBN:978-1-365-78192-6 